\title{
GMR
}

\section{Association of NF-кB1 gene polymorphisms with coronary artery disease in a Han Chinese population}

\author{
X.L. Guo, X.C. Liu, G.B. Su, C.Y. Zhou and Q.T. Cui \\ Department of Cardiothoracic Surgery, \\ First Affiliated Hospital of Xinxiang Medical University, Xinxiang, Henan, \\ China \\ Corresponding author: Q.T. Cui \\ E-mail: cuiqingtao1978@163.com \\ Genet. Mol. Res. 15 (3): gmr. 15038072 \\ Received November 17, 2015 \\ Accepted January 22, 2016 \\ Published July 29, 2016 \\ DOI http://dx.doi.org/10.4238/gmr.15038072
}

Copyright $($ C) 2016 The Authors. This is an open-access article distributed under the terms of the Creative Commons Attribution ShareAlike (CC BY-SA) 4.0 License.

\begin{abstract}
Nuclear factor (NF)- $\mathrm{kB}$ is a transcription factor that controls cell proliferation, differentiation, and immunity. Activated $\mathrm{NF}-\mathrm{\kappa B} 1$ is associated with the pathogenesis of coronary artery disease (CAD) and genetic polymorphisms in NF-kB1 have a plausible role in modulating the risk of CAD. To identify markers that contribute to the genetic susceptibility to $\mathrm{CAD}$, we examined the potential association between $\mathrm{CAD}$ and single nucleotide polymorphisms (SNPs; rs28362491, rs230531, rs230528, rs1005819, rs4648055, rs3774964, and rs3774968) in the NF-кB1 gene using SNaPshot SNP genotyping assay. Participants included 361 patients with CAD and 385 healthy controls. The genotype and allele frequencies of the rs28362491 (promoter region) polymorphism in the CAD patients were significantly different from those in the healthy controls. The frequency of the $\mathrm{D}$ allele was significantly higher in $\mathrm{CAD}$ patients than
\end{abstract}

Genetics and Molecular Research 15 (3): gmr.15038072 
in the healthy controls ( $\mathrm{P}=0.005$ after Bonferroni correction). Strong linkage disequilibrium was observed in one block (D'>0.9). Haplotype analysis revealed that haplotypes in block 1 of the NF- $\kappa$ B1 gene did not display a risk or protective effect $(\mathrm{P}>0.05)$. These data suggest that NF- $\mathrm{KB} 1$ gene polymorphisms confer susceptibility to CAD and also support the notion that dysfunction of NF- $\mathrm{KB} 1$ is involved in the pathophysiological process of CAD.

Key words: Coronary artery disease; Single nucleotide polymorphisms; Nuclear factor- $\mathrm{kB}$

\section{INTRODUCTION}

Coronary artery disease (CAD) is the most common type of heart disease. Health data compiled from more than 190 countries shows that heart disease remains the number one global cause of death with 17.3 million deaths each year. CAD is a complex and multisystem disease and has multifactorial etiologies. Multiple studies have provided evidence that genetic factors, including polymorphisms in several candidate genes, may interact with environmental modulators to promote CAD and increase risk of cardiovascular disease (Salazar et al., 2000; Nordlie et al., 2005).

NF-kappa-B (NF-kB) is a pleiotropic transcription factor present in almost all cell types and the endpoint of a series of signal transduction events that are initiated by a vast array of stimuli related to many biological processes such as inflammation, immunity, differentiation, cell growth, tumorigenesis, and apoptosis (Monaco and Paleolog, 2004). NF$\kappa \mathrm{B}$ is a homo- or hetero-dimeric complex formed by the Rel-like domain-containing proteins

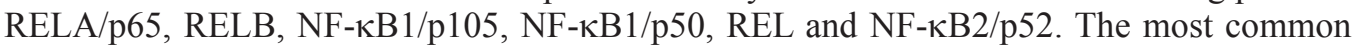
dimer is the $\mathrm{p} 65 / \mathrm{p} 50$ heterodimer (Stirrat, 1990). Atherosclerosis is a chronic inflammatory disease of the arterial wall (Libby, 2012). NF- $\mathrm{KB}$-mediated vascular inflammation plays a critical role in the initiation and progression of atherosclerosis. Therefore, activation of NF- $\kappa \mathrm{B}$ may be considered an important contributor to the development of CAD (Yang et al., 2014). The NF- $\mathrm{kB} 1$ promoter variant was associated with a higher risk of CAD in three independent prospective studies of generally healthy Caucasians (Vogel et al., 2011), indicating a potential linkage of NF- $\mathrm{kB} 1$ gene polymorphism and risk of CAD in the general population.

In this study, we investigated 7 loci (rs28362491, rs230531, rs230528, rs1005819, rs4648055, rs3774964, and rs3774968) in a Chinese population from He'nan province (China) to verify the putative association between NF- $\mathrm{kB} 1$ polymorphisms and CAD.

\section{MATERIAL AND METHODS}

\section{Subjects}

A total of 361 unrelated patients with $\mathrm{CAD}$ (mean age $=62.1 \pm 6.8$ years) were recruited from the First Affiliated Hospital of Xinxiang Medical University. The patients received the following lab examinations: coronary angiography, electrocardiogram (EKG), blood test, and/ or stress test. The interview was also performed on the patients. Inclusion criteria were: 1) patients had at least one diseased vessel ( $\geq 25 \%$ stenosis) in coronary angiograph; 2 ) patients

Genetics and Molecular Research 15 (3): gmr.15038072 
with stable angina pectoris (SAP) had a long-term and stable effort angina that had lasted for at least three months and a positive stress test; 3) patients with unstable angina pectoris had either angina with a progressive crescendo pattern or angina that occurred at rest without a recent myocardial infarction; 4) patients presented with transient ST-T segment depression and T-wave inversion without significantly elevated levels of cardiac enzymes; and 5) patients with acute myocardial infarction presented with typical angina associated with ST-segment elevations in EKG, and the frequency of occurrence of elevated levels of creatine kinase and troponin-I in serum were more than 3. Exclusion criteria were non-cardiac diseases including acute or chronic infections, malignancies, autoimmune diseases, hyperthyroidism, or medication with immunosuppressive agents. The control group consisted of 385 unrelated healthy subjects (mean age $=61.8 \pm 6.2$ years) who underwent health examinations in the Medical Examination Center of the First Affiliated Hospital of the Xin'xiang Medical College (China). The patients with angina-like symptoms and a suspected diagnosis of CAD were excluded by coronary angiogram. The subjects with diabetes mellitus or hyperlipidemia were excluded. All participants were from a non-genetically-related Chinese Han population in He'nan Province (China). The study was performed according to the Guidelines of the Medical Ethical Committee of Xin'xiang Medical College (Xinxiang, China). Written informed consent was obtained from all the participants recruited in this study.

\section{Genotyping}

Peripheral venous blood was drawn into a sterile tube containing ethylenediamine tetraacetic acid. Plasma samples were stored at $-20^{\circ} \mathrm{C}$. Genomic DNA was extracted from frozen peripheral blood samples using a QIAmp Blood Mini Kit (Qiagen Inc., Valencia, CA, USA) according to the manufacturer protocols. Genotyping was performed using SNaPshot single nucleotide polymorphism (SNP) genotyping assay (Genesky, Shanghai, China). The touch-down polymerase chain reaction was carried out in a $20-\mu \mathrm{L}$ reaction mixture. Next, the SNaPshot multiplex single-base extension reaction was performed in a $10-\mu \mathrm{L}$ reaction volume. After purification using $1 \mathrm{U}$ SAP for $60 \mathrm{~min}$ at $37^{\circ} \mathrm{C}$ followed by $15 \mathrm{~min}$ at $75^{\circ} \mathrm{C}$, the extension reaction product was separated using capillary electrophoresis (ABI 3130XL Genetic Analyzer, Applied Biosystems Co Ltd., USA) and the results were analyzed using the GeneMapper 4.1 software (Applied Biosystems Co Ltd.). Fifty samples were selected randomly to repeat genotyping for quality control and the repeat accuracy was $100 \%$.

\section{Statistical analysis}

The allele and genotype frequencies for each individual polymorphism were compared, and Hardy-Weinberg equilibrium (HWE) was evaluated using the chi-square test. Pearson's chisquared $\left(\chi^{2}\right)$ test was used to evaluate the differences in the distribution of the categorical variables, including the known risk factors and frequencies of the NF- $\mathrm{BB} 1$ genotypes, alleles, and haplotypes. A logistic regression analysis was conducted to calculate the adjusted odds ratios and $95 \%$ confidence intervals for associations between the genetic polymorphisms and CAD risk. Pair-wise linkage disequilibrium (LD) statistics (D' and $\mathrm{r}^{2}$ ) and haplotype frequency were calculated, and haplotype blocks were constructed using Haploview 4.0. To ensure that the LD blocks most closely reflect the population level LD patterns, definition of the blocks was based on the control samples alone. All data were analyzed using the SPSS 20.0 software (SPSS Inc., Chicago, IL, USA).

Genetics and Molecular Research 15 (3): gmr.15038072 


\section{RESULTS}

No significant deviation from HWE was found in cases or controls for any of the SNPs. LD analysis of the patients and controls revealed that the six downstream SNPs are located in a haplotype block (Figures 1 and 2). The genotype distribution, allelic frequencies, and haplotypes in the patients with CAD and healthy controls are shown in Tables 1 and 2.

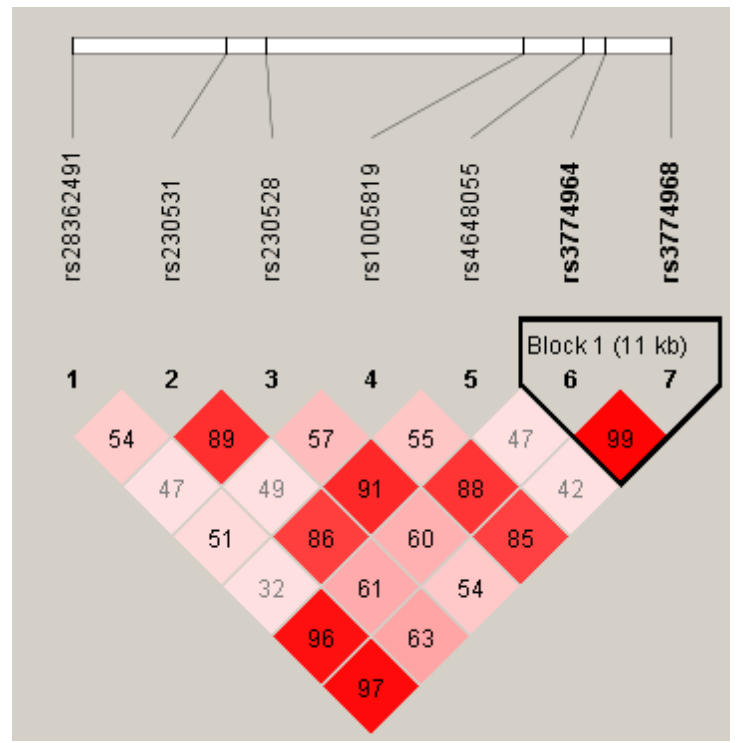

Figure 1. LD plot for the $7 \mathrm{SNPs}$ in the NF- $\mathrm{KB} 1$ gene. Values in squares are the pair-wise calculation for $\mathrm{r}^{2}$.

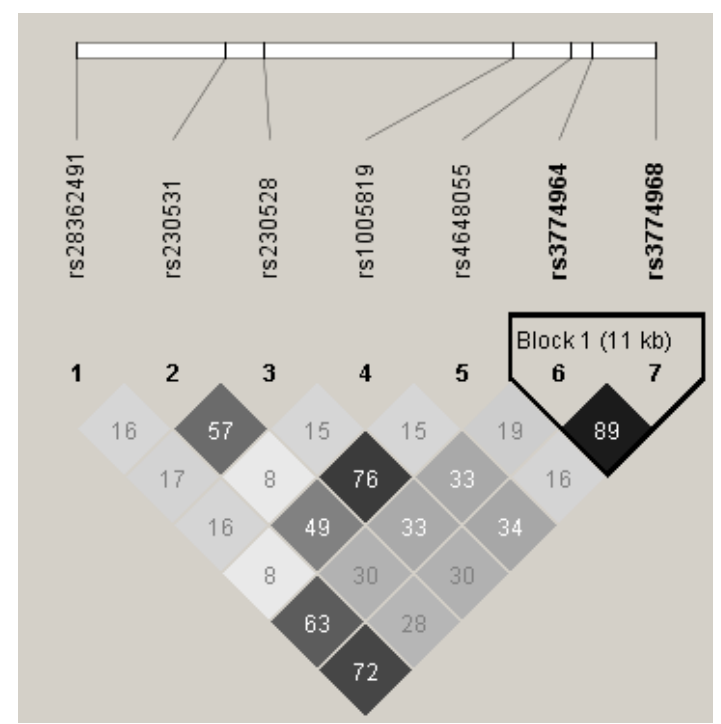

Figure 2. LD plot for the 7 SNPs in NF-kB1 gene in controls. Values in squares are the pair-wise calculation for D'.

Genetics and Molecular Research 15 (3): gmr.15038072 
Table 1. Genotype and allele frequencies of NF- $\mathrm{\kappa B} 1$ polymorphisms in the controls and patients with CAD.

\begin{tabular}{|c|c|c|c|c|c|c|c|c|}
\hline \multirow[t]{2}{*}{ Variable } & \multirow[t]{2}{*}{ MAF } & \multicolumn{2}{|c|}{$\mathrm{CAD}(\mathrm{N}=361)$} & \multicolumn{2}{|c|}{ Controls $(\mathrm{N}=385)$} & \multirow[t]{2}{*}{ HWE P value } & \multirow[t]{2}{*}{$\mathrm{P}_{\text {value }}^{\mathrm{a}}$} & \multirow[t]{2}{*}{ OR, 95\%CI } \\
\hline & & No. & $\%$ & No. & $\%$ & & & \\
\hline rs28362491 & 0.461 & & & & & 0.179 & 0.001 & \\
\hline SS & & 109 & 30.2 & 72 & 18.7 & & 0.000281 & $1.880,1.337-2.644$ \\
\hline SD & & 167 & 46.3 & 211 & 54.8 & & 0.020 & $0.710,0.532-0.947$ \\
\hline DD & & 85 & 23.5 & 102 & 26.5 & & 0.353 & $0.854,0.613-1.191$ \\
\hline S allele & & 385 & 53.3 & 355 & 46.1 & & 0.005 & $1.336,1.089-1.637$ \\
\hline D allele & & 337 & 46.7 & 415 & 53.9 & & & \\
\hline rs230531 & 0.381 & & & & & 0.519 & 0.442 & \\
\hline TT & & 150 & 41.6 & 144 & 37.4 & & 0.247 & $1.190,0.887-1.596$ \\
\hline $\mathrm{CT}$ & & 161 & 44.6 & 189 & 49.1 & & 0.219 & $0.835,0.626-1.114$ \\
\hline $\mathrm{CC}$ & & 50 & 13.9 & 52 & 13.5 & & 0.891 & $1.030,0.678-1.564$ \\
\hline $\mathrm{T}$ allele & & 461 & 63.9 & 477 & 61.9 & & 0.447 & $1.085,0.879-1.339$ \\
\hline $\mathrm{C}$ allele & & 261 & 36.1 & 293 & 38.1 & & & \\
\hline rs 230528 & 0.468 & & & & & 0.265 & 0.343 & \\
\hline $\mathrm{CC}$ & & 89 & 24.7 & 112 & 29.1 & & 0.173 & $0.798,0.576-1.104$ \\
\hline $\mathrm{CA}$ & & 191 & 52.9 & 186 & 48.3 & & 0.210 & $1.202,0.902-1.602$ \\
\hline$\overline{\mathrm{AA}}$ & & 81 & 22.4 & 87 & 22.6 & & 0.958 & $0.991,0.703-1.397$ \\
\hline $\mathrm{C}$ allele & & 369 & 51.1 & 410 & 53.2 & & 0.409 & $0.918,0.749-1.125$ \\
\hline A allele & & 353 & 48.9 & 360 & 46.8 & & & \\
\hline rs1005819 & 0.339 & & & & & 0.360 & 0.982 & \\
\hline $\mathrm{CC}$ & & 153 & 42.4 & 163 & 42.3 & & 0.990 & $1.002,0.749-1.340$ \\
\hline $\mathrm{CT}$ & & 170 & 47.1 & 183 & 47.5 & & 0.904 & $0.982,0.737-1.310$ \\
\hline TT & & 38 & 10.5 & 39 & 10.1 & & 0.859 & $1.044,0.651-1.673$ \\
\hline $\mathrm{C}$ allele & & 476 & 65.9 & 509 & 66.1 & & 0.943 & $0.992,0.801-1.229$ \\
\hline $\mathrm{T}$ allele & & 246 & 34.1 & 261 & 33.9 & & & \\
\hline rs 4648055 & 0.486 & & & & & 0.269 & 0.833 & \\
\hline AA & & 96 & 26.6 & 110 & 28.6 & & 0.546 & $0.906,0.657-1.249$ \\
\hline GA & & 170 & 47.1 & 176 & 45.7 & & 0.706 & $1.057,0.792-1.410$ \\
\hline GG & & 95 & 26.3 & 99 & 25.7 & & 0.852 & $1.032,0.744-1.431$ \\
\hline $\mathrm{C}$ allele & & 362 & 50.1 & 396 & 51.4 & & 0.618 & $0.950,0.775-1.164$ \\
\hline A allele & & 360 & 49.9 & 374 & 48.6 & & & \\
\hline rs3774964 & 0.451 & & & & & 0.123 & 0.065 & \\
\hline AA & & 111 & 30.7 & 108 & 28.1 & & 0.419 & $1.139,0.831-1.561$ \\
\hline GA & & 165 & 45.7 & 207 & 53.8 & & 0.028 & $0.724,0.543-0.966$ \\
\hline GG & & 85 & 23.5 & 70 & 18.2 & & 0.072 & $1.386,0.972-1.977$ \\
\hline $\mathrm{C}$ allele & & 387 & 53.6 & 423 & 54.9 & & 0.605 & $0.948,0.773-1.162$ \\
\hline A allele & & 335 & 46.4 & 347 & 45.1 & & & \\
\hline rs3774968 & 0.477 & & & & & 0.179 & 0.065 & \\
\hline AA & & 109 & 30.2 & 96 & 24.9 & & 0.108 & $1.302,0.943-1.797$ \\
\hline GA & & 167 & 46.3 & 211 & 54.8 & & 0.020 & $0.710,0.532-0.947$ \\
\hline GG & & 85 & 23.5 & 78 & 20.3 & & 0.278 & $1.212,0.856-1.716$ \\
\hline $\mathrm{C}$ allele & & 385 & 53.3 & 403 & 52.3 & & 0.703 & $1.040,0.849-1.275$ \\
\hline A allele & & 337 & 46.7 & 367 & 47.7 & & & \\
\hline
\end{tabular}

aP value was calculated by $2 \times 3$ and $2 \times 2$ chi-squared tests based on codominant, dominant for the rare allele, and heterosis and recessive for the rare allele models of inheritance. Alpha value is adjusted by Bonferroni correction and statistically significant results $(\mathrm{P}<0.003)$.

Table 2. Haplotype in block 1 frequencies and their association with risk of CAD.

\begin{tabular}{l|c|c|c|c|c|c}
\hline Haplotype & Cases [N (\%)] & Controls [N (\%)] & \multicolumn{3}{|c}{ Statistics } \\
\cline { 4 - 7 } & & & $\chi^{2}$ & $\mathrm{P}^{*}$ & OR & $95 \% \mathrm{CI}$ \\
\hline AA & $194(53.740)$ & $202(52.468)$ & 0.121 & 0.728 & 1.052 & $0.789,1.403$ \\
\hline GG & $162(44.875)$ & $172(44.675)$ & 0.003 & 0.956 & 1.008 & $0.755,1.346$ \\
\hline
\end{tabular}

*P value is adjusted by Bonferroni correction and statistically significant results $(\mathrm{P}<0.025)$.

In this case-control association study, the analysis revealed a strong association between the rs 28362491 genotype distribution and CAD $(P=0.005)$. The frequency of the

Genetics and Molecular Research 15 (3): gmr.15038072 
rs28362491 SS and SD genotypes was significantly lower in CAD patients than in the healthy controls $(\mathrm{P}<0.05)$. Significantly more $\mathrm{D}$ alleles were found in the patients with CAD. There were no significant differences between the SNPs (rs230531, rs230528, rs1005819, rs4648055, rs3774964, and rs3774968) and CAD occurrence (Table 1).

We performed an association analysis to determine whether the haplotype was associated with risk of CAD (block 1). However, no significant haplotype association was found between CAD patients and healthy controls (Table 2).

\section{DISCUSSION}

A key step in linkage and association studies is to identify common risk variants in different populations. To identify markers contributing to genetic susceptibility to CAD, we examined 7 SNPs spanning the coding and non-coding regions of the NF- $\kappa B 1$ gene. We examined the effects of the NF- $\kappa$ B1 SNPs and predicted haplotypes of the LD block of the $\mathrm{NF}-\kappa \mathrm{B} 1$ gene on the genetic susceptibility to CAD in a Chinese Han population. During the past decade, much evidence has accumulated to support the role of NF- $\kappa B$ in CAD (Baker et al., 2009; Mishra et al., 2013). Our results provide genetic evidence that NF-кB1 is linked to $\mathrm{CAD}$ and extends to identify polymorphisms that may affect the development of CAD (Özbilüm et al., 2013; Yang et al., 2014; Arslan et al., 2015).

A common insertion (ins)/deletion (del) (-94 ins/del ATTG rs28362491) polymorphism

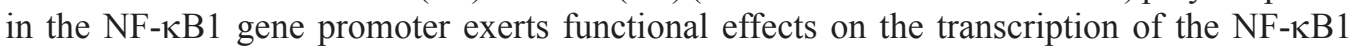
(Chen et al., 2015). Since the 4-bp ins/del polymorphism produces a relatively large sequence change and its location is proximal to binding sites that are important to promoter regulation, the ATTG deletion (D) allele displays significantly reduced promoter activity and is also involved in lowering levels of p50 protein. Yang et al. (2014) used two independent casecontrol studies including a Han population (633 CAD patients and 616 control subjects) and a Uygur population (437 CAD patients and 356 control subjects). They found that the DD genotype of the rs28362491 SNP in the NF- $\mathrm{BB} 1$ gene may be considered a genetic marker of CAD in Han and Uygur women in China. In this case-control association study, the A

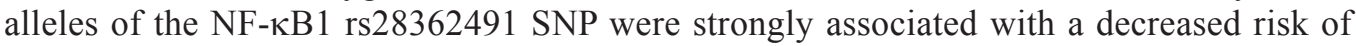
CAD. Our study included 361 CAD subjects and 385 healthy controls, which had sufficient statistical power to prove an epidemiologically relevant impact of hereditary variations among the studied genes. Arslan et al. (2015) found that the genotype frequency of NF$\kappa \mathrm{B} 1 \mathrm{rs} 28362491 \mathrm{DD}$ in the CAD group was significantly higher compared to the controls. These NF-кB1 gene variations may induce a change in mRNA secondary structure, which could in turn affect the stability, processing, or subcellular targeting of the mRNA transcript and thereby alter splicing, transcription, and the efficiency of translation. The mechanism by which the rs28362491 SNP affects susceptibility to CAD is that the SNP may affect the function of the NF- $\kappa B 1$ protein rather than its expression. These results indicate that the rs28362491 D allele is a risk factor for CAD.

In conclusion, with a relatively large sample size and a homogeneous sampling population, we found a NF- $\kappa$ B1 gene polymorphism (rs28362491) was associated with CAD. The results of this and similar future studies could help to better understand the molecular mechanisms of CAD, allowing us to devise better treatment strategies.

Genetics and Molecular Research 15 (3): gmr.15038072 


\section{Conflicts of interest}

The authors declare no conflict of interest.

\section{ACKNOWLEDGMENTS}

Research supported by supported by the Henan Province Science and Technology Research and Development Program (\#2015K11-06-06-03).

\section{REFERENCES}

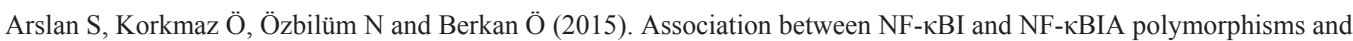
coronary artery disease. Biomed. Rep. 3: 736-740.

Baker AR, Harte AL, Howell N, Pritlove DC, et al. (2009). Epicardial adipose tissue as a source of nuclear factor-kappaB and c-Jun N-terminal kinase mediated inflammation in patients with coronary artery disease. J. Clin. Endocrinol. Metab. 94: 261-267.http://dx.doi.org/10.1210/jc.2007-2579

Chen Y, Lu R, Zheng H, Xiao R, et al. (2015). The NFKB1 polymorphism (rs4648068) is associated with the cell proliferation and motility in gastric cancer. BMC Gastroenterol. 15: 21. http://dx.doi.org/10.1186/s12876-015-0243-0

Libby P (2012). Inflammation in atherosclerosis. Arterioscler. Thromb. Vasc. Biol. 32: 2045-2051. http://dx.doi. org/10.1161/ATVBAHA.108.179705

Mishra A, Srivastava A, Mittal T, Garg N, et al. (2013). Role of inflammatory gene polymorphisms in left ventricular dysfunction (LVD) susceptibility in coronary artery disease (CAD) patients. Cytokine 61: 856-861. http://dx.doi. org/10.1016/j.cyto.2012.12.020

Monaco C and Paleolog E (2004). Nuclear factor kappaB: a potential therapeutic target in atherosclerosis and thrombosis. Cardiovasc. Res. 61: 671-682. http://dx.doi.org/10.1016/j.cardiores.2003.11.038

Nordlie MA, Wold LE and Kloner RA (2005). Genetic contributors toward increased risk for ischemic heart disease. $J$. Mol. Cell. Cardiol. 39: 667-679. http://dx.doi.org/10.1016/j.yjmcc.2005.06.006

Özbilüm N, Arslan S, Berkan Ö, Yanartaş M, et al. (2013). The role of NF-אB1A promoter polymorphisms on coronary artery disease risk. Basic Clin. Pharmacol. Toxicol. 113: 187-192. http://dx.doi.org/10.1111/bcpt.12085

Salazar LA, Hirata MH, Giannini SD, Forti N, et al. (2000). Seven DNA polymorphisms at the candidate genes of atherosclerosis in Brazilian women with angiographically documented coronary artery disease. Clin. Chim. Acta 300: 139-149. http://dx.doi.org/10.1016/S0009-8981(00)00308-9

Stirrat GM (1990). Recurrent miscarriage. Lancet 336: 673-675.http://dx.doi.org/10.1016/0140-6736(90)92159-F

Vogel U, Jensen MK, Due KM, Rimm EB, et al. (2011). The NFKB1 ATTG ins/del polymorphism and risk of coronary heart disease in three independent populations. Atherosclerosis 219: 200-204. http://dx.doi.org/10.1016/j. atherosclerosis.2011.06.018

Yang YN, Zhang JY, Ma YT, Xie X, et al. (2014). -94 ATTG insertion/deletion polymorphism of the NFKB1 gene is associated with coronary artery disease in Han and Uygur women in China. Genet. Test. Mol. Biomarkers 18: 430438. http://dx.doi.org/10.1089/gtmb.2013.0431

Genetics and Molecular Research 15 (3): gmr.15038072 